\title{
Personality Profile of Risk Takers: An Examination of the Big Five Facets
}

\author{
Elizabeth Joseph ${ }^{1} \&$ Don C. Zhang ${ }^{2}$ \\ ${ }^{1}$ Louisiana State University, Now at Texas Christian University \\ ${ }^{2}$ Louisiana State University
}

\begin{abstract}
Version Note
This manuscript has been accepted for publication at Journal of Individual Differences. This version is not the final copy of record and may not reflect the final, authoritative version of the article. Please cite as: Joseph E. D. \& Zhang, D.C., (2021, in press). Personality profile of risk takers: An examination of the Big Five facets. Journal of Individual Differences
\end{abstract}

Author Note

Correspondence concerning this article may be addressed to Don C. Zhang, Department of Psychology, Louisiana State University. Email: zhang1@1su.edu. We are grateful for Janet McDonald and Ginger Stevens for their thoughtful feedback on earlier version of this paper. 


\begin{abstract}
Risk taking is a long-standing area of inquiry among psychologists and economists. In this paper, we examine the personality profile of risk takers in two independent samples.

Specifically, we examined the association between the Big Five facets and risk-taking propensity across two measures: The Domain-Specific Risk-Taking Scale (DOSPERT) and the General Risk Propensity Scale (GRiPS). At the Big Five domain level, we found that extraversion and agreeableness were the primary predictors of risk taking. However, facet-level analyses revealed that responsibility, a facet of conscientiousness, explained most of the total variance accounted for by the Big Five in both risk-taking measures. Based on our findings across two samples $(\mathrm{n}=$ 764), we find that the personality profile of a risk taker is extraverted, open to experiences, disagreeable, emotionally stable, and irresponsible. Implications for the risk measurement are discussed.

Keywords: Risk preferences, Big Five personality, individual differences, psychometrics, DOSPERT
\end{abstract}




\section{Personality Profile of Risk Takers: An Examination of the Big Five Facets}

Individual differences in risk taking propensity is a long-standing area of inquiry for decision theorists, psychologists, and economists. On the one hand, risk takers are often synonymous with being reckless and irresponsible (Arnett, 1992; Lejuez et al., 2003). On the other hand, risk taking tendencies are also used to characterize successful entrepreneurs and investors (Kerr et al., 2019). Despite the strong interest in risk taking, there is discord amongst the scientific community about the nature of risk-taking as a general personality disposition (Fox \& Tannenbaum, 2011; Frey et al., 2017; Hanoch et al., 2006) and its position in the five-factor model (FFM) - the dominant model of personality (Lauriola \& Weller, 2018; Mata et al., 2018; McCrae \& Costa Jr, 1999; Paunonen \& Jackson, 2000).

Past research has typically conceptualized risk taking as a domain-specific phenomenon. The domain-specific perspective suggests that risk-taking behavior differs across domains such as finance, health and safety, ethics, recreation, and social (Weber et al., 2002). For example, an individual may be an avid gambler, which involves financial risk, but not be willing to smoke a cigarette because of the health risks. Recent research, however, has supported the domaingeneral perspective of risk-taking. Frey, Pedroni, Mata, Rieskamp, and Hertwig (2017) found evidence for a general risk factor, which explained shared variance across 39 risky measures. The authors concluded that risk-taking - like personality - could be considered a domain-general and situationally consistent psychological trait (Also see Highhouse, Nye, Zhang, \& Rada, 2017).

From a personality perspective, past researchers have also disagreed on how to classify risk-taking within the existing structure of personality. Specifically, it is uncertain whether risktaking falls within the Five Factor Model (FFM) of personality or as a distinct trait (Paunonen \& 
Jackson, 2000). In their comprehensive lexical study of personality adjectives, Paunonen and Jackson observed several personality traits - including risk-taking - that are not represented within the Big Five (also see Lee, Ogunfowora, \& Ashton, 2005). Subsequent research on dispositional risk taking within the Big Five framework, however, has been disjointed due to arguably - the long-espoused view summarized by Figner and Weber (2011): “ $\ldots$ risk taking is neither a unitary phenomenon nor a single personality trait" (p. 211). Considering the recent theoretical and empirical developments in risk research, it is important to clarify the location of general risk propensity within the Big Five.

Although some research has examined the relative contribution of the Big Five for risktaking, a majority of existing work has used mostly domain-specific measures (e.g., Barnes et al., 2012; Nicholson et al., 2005; Weller \& Tikir, 2011) or only examined the Big Five at the domain-level (e.g., Lauriola \& Levin, 2001; Zhang, Highhouse, \& Nye, 2018). Domain-level analyses of the Big Five may overlook important facet-level associations. For example, the Big Five domain extraversion is defined as outgoing/energetic vs. solitary/reserved. Within extraversion, however, there are narrow facets such as sociability, energy level, and assertiveness. According to Soto and John (2017), the domain-level scales provide a broad overview of the traits, whereas the facet-level subscales provide more descriptive facets in those domains that can be used to identify corresponding behaviors.

The methodological shortcomings of past research may obscure the true associations between risk-taking and the Big Five. First, studies that only measure the Big Five at the domain level are omitting important associations at the facet level. Consider the role of conscientiousness, as an example. Whereas the responsibility facet is likely to be very strongly associated with risk-taking, other facets such as organization and productivity are likely to play a 
lesser role. Consequently, the observed association between Big Five domains with risk taking may be attenuated when facets with differential validities are combined. Domain-level associations, therefore, may not provide a clear picture of where risk-taking fits within the Big Five. The second shortcoming pertains to the measurement of general risk-taking propensity. Most past research has focused on the relations between personality and domain-specific risktaking. In other words, researchers have assumed that - because risk-taking varies across domains - there must be unique correlates between each Big Five trait with risk-taking in each domain (e.g., Nicholson et al., 2005). While this is true, this line of work has discounted domaingeneral consistencies in risk-taking, which has only been recently brought to light (Highhouse et al., 2017).

In the present study, we used relative weight analysis (RWA) to examine the relative contribution of the Big Five facets on risk-taking measured with two risk-taking instruments: The Domain-Specific Risk-Taking Scale (DOSPERT, Weber et al., 2002) and the General Risk Propensity Scale (GRiPS, Zhang, et al., 2018). The DOSPERT has been one of the most widely used measures of risk-taking, and many researchers combine the domain scores of the DOSPERT to form an overall measure of risk propensity (Mishra et al., 2010; Szrek et al., 2012). However, the summated DOSPERT score may not be equivalent to an instrument designed to measure general risk propensity (Ironson et al., 1989). The GRiPS was recently developed as a direct measure of general risk-taking propensity and explained incremental variance in several broad outcomes above the DOSPERT - suggesting that the two measures may not be completely equivalent. A secondary purpose of this paper, therefore, is to explore the divergence in the two instruments as measures of general risk-taking by examining their patterns of associations with the Big Five facets. By examining the nomological network of risk-taking in relation to the Big 
Five, we aim to shed light on the construct validity for the two measures of general risk-taking propensity.

\section{Methods}

\section{Participants}

Sample 1. Two hundred and ninety-five college students were recruited to participate in the study. Students were recruited via SONA, a cloud-based subject pool designed to be used at universities. Participants received a SONA credit for participation in each survey. We removed 45 participants for excessive missing data (50\% or more missing) and 11 participants for missing one of the two attention check questions (e.g., "Please select strongly disagree"). The final sample contained 239 participants $(70 \%$ female, mean age $=19$ [SD $=1.38] ; 44 \%$ freshmen, $23 \%$ sophomore, $20 \%$, junior, $12 \%$ senior).

Sample 2. Five hundred and eighty participants were recruited using Prolific.co, an online crowdsourcing platform for social science research. We removed 55 participants for missing more than one out of three attention check questions (e.g., "Please select strongly disagree"). The final sample contained 525 participants $(50 \%$ female, mean age $=37$ [SD $=12]$; $71 \%$ Caucasian).

\section{Measures}

General Risk Propensity Scale (GRiPS). The GRiPS is an eight-item, self-report scale that measures general risk-taking propensity (Zhang, et al., 2018). It is used to measure participants' general propensity for risk-taking across domains. Participants were presented with short statements that describe aspects of their personality and indicated, on a 5-point Likert scale $(1=$ strongly disagree to $5=$ strongly agree $)$, the degree to which they agree or disagree with each statement. The GRiPS was administered to both Samples 1 and 2. 
Domain-Specific Risk-Taking Scale (DOSPERT). The DOSPERT is a 30-item self-

report measure of domain-specific risk-taking propensity. It measures risk-taking in five different areas: financial, health/safety, recreational, and social (Blais and Weber, 2006). Participants are asked to indicate the likelihood that they would engage in an activity or behavior by providing a rating from 1 (extremely unlikely) to 7 (extremely likely). In addition to the domain-specific risk taking scores, we also created a summated total risk taking score by aggregating across all thirty items. The DOSPERT was administered to both Samples 1 and 2.

\section{Big Five Personality}

The BFI-2. The BFI-2 is a 60-item self-report measure of the Big Five personality (Soto \& John, 2017). It measures five personality traits: extraversion (e.g., "is outgoing, sociable”), agreeableness (e.g., "has a forgiving nature”), conscientiousness (e.g., "is dependable, steady"), negative emotionality (e.g., "can be moody"), and open-mindedness (e.g., "values artistic, aesthetic experience"). In addition to the five personality traits, the BFI-2 also measures 15 facets associated with each of the personality traits. For example, the trait conscientiousness can be further broken down into the facets of responsibility, productiveness, and organization (See Tables 2 and 3 for a list of facets and corresponding Big Five dimensions). Participants were presented with short statements that describe aspects of their personality and indicated, on a 5point Likert scale $(1=$ strongly disagree to $5=$ strongly agree $)$, the degree to which they agree or disagree with each statement. The BFI-2 was administered to Sample 1.

IPIP-NEO-60. The IPIP-NEO-60 is a 60-item self-report measure of the Big Five personality developed from the International Personality Item Pool (IPIP) (Maples-Keller et al., 2019). Participants were presented with short statements that describe aspects of their personality and indicated, on a 5-point Likert scale $(1=$ strongly disagree to $5=$ strongly agree $)$, the degree 
to which they agree or disagree with each statement. The IPIP-NEO-60 was administered to Sample 2. In addition to Big Five dimensions, we also calculated scores for the 15 personality facets. Appendix A contains a list of corresponding facets between the BFI-2 and IPIP-NEO-PI60.

\section{Results}

The means, standard deviations and scale reliabilities of risk taking and Big Five dimensions for both samples are listed in Tables 1 and 2. Multiple regression and relative weight analysis (RWA) were conducted to examine the unique contributions of the Big Five facets for predicting risk-taking. RWA is particularly useful when one is interested in the unique contribution of correlated predictors to a criterion (Tonidandel \& LeBreton, 2011). RWA is often used to supplement the interpretation of multiple regressions because it provides additional information pertaining to the relative importance of predictors that are not present in traditional regression analysis. Specifically, it produces a percentage value that reflects the proportion of the explained variance that can be attributed to each predictor while simultaneously accounting for covariance between predictors. In this study, we used RWA to investigate the relative contribution of each Big Five facet for predicting domain-general and specific risk-taking.

\section{Big Five and General Risk-Taking Propensity}

We tested two separate regression models of Big Five and general risk-taking using the GRiPS and DOSPERT's total scale score in each of the two samples. First, multiple $R^{2}$ revealed that the BFI and NEO explained $42 \%$ and $38 \%$ of the total variance in the GRiPS and $33 \%$ and $37 \%$ of the total variance in the summated DOSPERT score (see Tables 3 and 4).

Examinations of the facet-level relations with general risk propensity measured with both the GRiPS and DOSPERT revealed consistent patterns. Specifically, the responsibility facet of 
conscientiousness had the highest bivariate correlation and relative weight index for predicting general risk-taking: each accounting for $36 \%$ and $37 \%$ of the total predicted variance for GRiPS and DOSPERT, respectively. Also notable is the consistent pattern of relations between each of the three extraversion facets and risk-taking. Specifically, the combination of the three facets (sociability, energy level, and assertiveness) accounted for $33 \%$ of the explained variance in GRiPS and $19.6 \%$ of the variance in DOSPERT. Finally, we found fairly consistent associations between risk-taking and agreeableness. Facet analysis further revealed that the respectful facet of agreeableness was the primary contributor to risk taking across both measures.

The relative contribution of both negative emotionality and open-mindedness domains were mixed between the two forms of risk measures. First, open-mindedness seemed to better predict risk-taking measured by the DOSPERT, whereas negative emotionality better predicted risk-taking measured by the GRiPS. Analyses of facet-level associations revealed that the intellectual curiosity facet of the open-mindedness dimension was the primary predictor of DOSPERT. And the anxiety facet of negative emotionality was the primary predictor of GRiPS. This divergence of associations suggests that the overall risk propensity score between a domaingeneral measure (e.g., GRiPS) and the summated score from a domain-specific measure (DOSPERT) may not be completely equivalent measures of the same construct.

\section{Big Five and Domain-Specific Risk Taking}

Multiple regression and relative weight analysis were also used to examine the associations between the Big Five and domain-specific risk taking. Tables 5 and 6 contain the results for the two samples. Multiple $R^{2}$ shows that the combination of the Big Five explained between $18 \%$ and $34 \%$ of the variance in domain-specific risk taking. Notably, the social domain 
had the highest overlap with the Big Five. Excluding the social dimension, the Big Five explained at most $28 \%$ of the variance in the remaining dimensions of risk taking.

Social Risk Taking. The Big Five explained 33\% and 34\% of the variance in social risk taking in the two samples. Social risk taking was most strongly predicted by the extraversion ( $r s$ $\left.=.26^{* *}, .26^{* *}\right)$ and openness $\left(r s=.37^{* *}, .50^{* *}\right)$ dimensions of the Big Five. Interestingly, social risk was negatively associated with the conscientiousness dimension $\left(r=-.23^{* *}\right)$ in the student sample, but the association was positive in the adult sample $(r=.09 *)$.

Ethical Risk Taking. The Big Five explained $25 \%$ and $27 \%$ of the variance in ethical risk taking in the two samples. Ethical risk was most strongly predicted by the agreeableness (rs $\left.=-.38^{* *},-.44^{* *}\right)$ and conscientiousness $\left(r s=-.35^{* *},-.38^{* *}\right)$ dimensions. Facet level analyses revealed a similar pattern of associations across the individual facets of each dimension. Unlike the other dimensions, ethical risk taking was not associated with extraversion or openness.

Financial Risk Taking. The Big Five explained $18 \%$ and $19 \%$ of the variance in financial risk taking in the two samples. The observed associations between Big Five and financial risk taking were modest. Across both samples, we found that financial risk taking was associated with cooperation/respect $(r s=-.21 * * ;-.24 * *)$, and cautiousness/responsibility $(r s=$ $\left..24^{* *} ;-.16^{* *}\right)$. Interestingly, we found a strong association with assertiveness in the adult sample $\left(\mathrm{r}=.23^{* *}\right)$ but not in the student sample $(\mathrm{r}=.08)$.

Recreational Risk Taking. The Big five explained $28 \%$ and $21 \%$ of the variance in recreational risk in the two samples. Recreational risk was most strongly predicted by extraversion $\left(r s=.34^{* *}, .39^{* *}\right)$. We also found a consistent but modest association between openness and recreational risk $\left(r s=.16^{*}, .20^{*}\right)$. Facet level analysis revealed that recreational 
risk was also predicted the responsibility/cautious facet of conscientiousness $\left(r s=-.31^{* *},-\right.$ $.14 * *)$ as well as the anxiety facet of neuroticism $\left(r s=-.16^{* *},-.22^{* *}\right)$.

Health Risk Taking. The Big Five explained $26 \%$ of the variance in health risk in both samples. Health risk was most strongly predicted by conscientiousness $\left(r s=-.25^{* *},-.23^{* *}\right)$ and agreeableness $\left(r s=-.24^{* *},-.27^{* *}\right)$ in both samples. The cautious/responsibility facet had the strongest associations with health risk taking $\left(r s=-.42^{* *},-.33^{* *}\right)$. Facet level analysis also revealed that health risk taking was strongly predicted by the sociability/gregarious facet of extraversion $(r s=.22 * *, .20 * *)$.

\section{Discussion}

Personality psychologists have theorized that risk-taking as a personality disposition may fall outside of, and distinct from, the Big Five model of personality. In this paper, we find that the Big Five explained between $33 \%$ and $42 \%$ of the total variance in risk-taking. As points of reference, the Big Five accounts for approximately $41 \%$ of the variance in psychopathy and $52 \%$ of subjective wellbeing (Anglim \& Grant, 2016; O'Boyle et al., 2015), both of which are theorized as distinct constructs. Furthermore, no single Big Five domain explained more than $20 \%$ of the variance in general risk-taking, which suggests that risk-taking propensity does not neatly fall under any single existing Big Five domain. Comparatively, Anglim, Morse, Dunlop, Minbashian, and Marty, (2019) found that extraversion alone explained $44 \%$ of the variance in emotional intelligence. Taken together, our findings suggest that general risk-taking is a relatively unique construct and may be better conceptualized as a compound trait that consists of multiple Big Five components (Credé et al., 2016). And that the profile of a risk-taker appears to be extraverted, open to experiences, disagreeable, emotionally stable, and irresponsible. 
The second purpose of the paper is to further examine the personality profile of risktakers. Consistent with past research, extraversion, openness, and agreeableness appear to be the strongest consistent predictor of risk-taking across both instruments. However, facet-level analysis revealed that responsibility/cautiousness - a facet of conscientiousness - was the primary personality predictor of general risk-taking across both instruments even though conscientiousness, overall, had moderate to low bivariate correlations with the DOPSERT and GRiPS (c.f. Nicholson, 2005). Furthermore, the responsibility facet was the most consistent facet-level predictor of all five domains of risk takin. We also found modest associations between the neuroticism dimension and risk taking. However, facet-level analysis revealed that the anxiety facet of neuroticism emerged as a primary predictor of risk taking across both samples. Our findings are consistent with past research that shows the link between anxiety and risk taking (Hartley \& Phelps, 2012). Although some have suggested that other negative emotions, such as anger, may amplify risk taking (Lerner \& Keltner, 2001), we did not find such support. It is worth mentioning that our measure pertains to dispositional aspects of anger where past research linking anger to risk taking tend to focus on momentary emotions. Our findings illustrate the value of facet-level analyses, as they provide insight on unique personality correlates of risk-taking that would otherwise be ignored when only Big Five domains are considered.

Despite observing relatively consistent patterns of associations between Big Five dimensions and general risk taking across samples and measures, we still found substantial variability in Big Five associations across different domains of risk taking. Specifically, we find that social and recreational risk taking tend to be more strongly associated with the extraversion and openness dimensions of the Big Five whereas health and ethical risks were more strongly 
associated with conscientiousness and agreeableness. These findings are consistent with the Big Three conceptualization of personality and risk taking (Zuckerman et al., 1993). Within the Big Three framework, consciousness and agreeableness are conceptualized as dimensions subordinate to the disinhibition factor, which reflects people's tendency to behave in a controlled manner per social norms (Eysenck et al., 1985; Markon et al., 2005). Accordingly, traits related to inhibition are expected to be associated with risk taking behaviors that are maladaptive (e.g., health and financial risks) and antisocial (e.g., ethical risks). In contrast, extraversion and openness are theorized to reflect tendencies to seek excitement and novelty, which reflects the positive emotionality aspect of the Big Three. Past research suggests that both extraversion and openness take risks to seek new experiences to promote positive emotions (e.g., social risks and recreational risks), rather than risks that violate norms and expectations.

From a measurement perspective, we found similar patterns of associations with the Big Five for both the DOSPERT and GRiPS. The only point of minor divergences pertains to the anxiety facet. Our results suggest that anxiety is more strongly correlated with general risk taking measured with the GRiPS than the summated DOSPERT. Though, it is worth mention that the difference in the observed zero-order effect sizes is modest. These findings suggest that a short measure of general risk taking (i.e., GRiPS) serves as a construct valid proxy of general risk taking across various domains. This is further supported by the high convergent validity between the two measures of risk taking. Still, the variation in personality predictors of domain-specific risk taking suggests that if the goal of the research is to predict a specific set of risk-taking behaviors, then a domain-specific measure of risk-taking is ideal.

From a practical perspective, our findings suggest that risk propensity as a disposition may be a double-edged sword for real-world behaviors. On the one hand, risk-takers are 
extraverted and emotionally stable, which are qualities that promote positive life and work outcomes. On the other hand, risk-takers also tend to be irresponsible and reckless. These findings suggest that risk-takers may simultaneously be an asset and a liability in an organizational setting and will likely depend on the characteristics of the environment (Judge \& Zapata, 2015). Additional research is needed to unpack how general risk-taking propensity affects work, life, and educational outcomes.

\section{Limitations and Future Directions}

Several potential limitations should be addressed. The number of excluded participants in the sample due to careless responding was notable. However, the number of participants who responded carelessly (11 out of 239 in sample 1; 55 out of 580) is consistent with the number generally observed in the literature ( $10 \%$; Meade \& Craig, 2012). Second, the current study did not analyze potential interactions between traits and domains of risk taking. Although our study reported the differential patterns of personality-risk taking associations across domains, the specific patterns of these associations warrants further inquiry. Future research should also examine how Big Five personality differentially predict risk taking in adaptive (e.g., entrepreneurship) vs. maladaptive domains (e.g., reckless driving) (Herzberg, 2009; Kerr et al., 2019). Relatedly, trait $x$ trait interactions between Big Five facets may provide further explanatory power for risk taking in different domains. For example, individuals who are open to experience but low on consciousness may be more likely to pursue reckless risks. Finally, our study was cross-sectional, and therefore, may be susceptible to common method variance, which may artificially amplify or weaken the true relationship between variables (Spector, 2006). Future research should adopt a mix-method approach such as peer-reports or alternative measures of risk propensity. Though, researchers should exercise caution when using laboratory 
measures, as they may not capture the same underlying constructs as self-report measures of risk taking (Millroth et al., 2020; Pedroni et al., 2017).

\section{Conclusion}

Individual differences in risk taking has garnered substantial interest from psychologists, economists, and clinicians in the past decade. Emergent research has uncovered the dispositional qualities of risk taking, which has led some to position risk taking propensity as a stable personality trait. Our research advances the literature by examining the position of risk propensity with the specific facets within five factor model of personality. Our findings suggest that risk propensity stands as a construct that is related to, but distinct from the Big Five personality. Together, the personality profile of a risk taker is extraverted, open to experiences, disagreeable, emotionally stable, and irresponsible. 


\section{References}

Anglim, J., \& Grant, S. (2016). Predicting Psychological and Subjective Well-Being from Personality: Incremental Prediction from 30 Facets Over the Big 5. Journal of Happiness Studies, 17(1), 59-80. https://doi.org/10.1007/s10902-014-9583-7

Anglim, J., Morse, G., Dunlop, P. D., Minbashian, A., \& Marty, A. (2019). Predicting trait emotional intelligence from HEXACO personality: Domains, facets, and the general factor of personality. Journal of Personality, jopy.12493.

https://doi.org/10.1111/jopy.12493

Arnett, J. (1992). Reckless behavior in adolescence: A developmental perspective. Developmental Review, 12(4), 339-373.

Barnes, C. D., Brown, R. P., \& Tamborski, M. (2012). Living dangerously: Culture of honor, risk-taking, and the nonrandomness of "accidental" deaths. Social Psychological and Personality Science, 3(1), 100-107.

Credé, M., Harms, P. D., Blacksmith, N., \& Wood, D. (2016). Assessing the Utility of Compound Trait Estimates of Narrow Personality Traits. Journal of Personality Assessment, 98(5), 503-513. https://doi.org/10.1080/00223891.2016.1170023

Eysenck, S. B., Eysenck, H. J., \& Barrett, P. (1985). A revised version of the psychoticism scale. Personality and Individual Differences, 6(1), 21-29.

Figner, B., \& Weber, E. U. (2011). Who Takes Risks When and Why?: Determinants of Risk Taking. Current Directions in Psychological Science, 20(4), 211-216. https://doi.org/10.1177/0963721411415790

Fox, C. R., \& Tannenbaum, D. (2011). The elusive search for stable risk preferences. Frontiers in Psychology, 2. http://www.ncbi.nlm.nih.gov/pmc/articles/PMC3216019/ 
Frey, R., Pedroni, A., Mata, R., Rieskamp, J., \& Hertwig, R. (2017). Risk preference shares the psychometric structure of major psychological traits. Science Advances, 3(10). https://doi.org/10.1126/sciadv.1701381

Hanoch, Y., Johnson, J. G., \& Wilke, A. (2006). Domain specificity in experimental measures and participant recruitment an application to risk-taking behavior. Psychological Science, 17(4), 300-304.

Hartley, C. A., \& Phelps, E. A. (2012). Anxiety and decision-making. Biological Psychiatry, $72(2), 113-118$.

Herzberg, P. Y. (2009). Beyond “accident-proneness": Using Five-Factor Model prototypes to predict driving behavior. Journal of Research in Personality, 43(6), 1096-1100.

Highhouse, S., Nye, C. D., Zhang, D. C., \& Rada, T. B. (2017). Structure of the Dospert: Is There Evidence for a General Risk Factor? Journal of Behavioral Decision Making. http://onlinelibrary.wiley.com/doi/10.1002/bdm.1953/full

Ironson, G. H., Smith, P. C., Brannick, M. T., \& Gibson, W. M. (1989). Construction of a Job in General scale: A comparison of global, composite, and specific measures. Journal of Applied Psychology, 74(2), 193-200. https://doi.org/10.1037/0021-9010.74.2.193

Judge, T. A., \& Zapata, C. P. (2015). The Person-Situation Debate Revisited: Effect of Situation Strength and Trait Activation on the Validity of the Big Five Personality Traits in Predicting Job Performance. Academy of Management Journal, 58(4), 1149-1179. https://doi.org/10.5465/amj.2010.0837

Kerr, S. P., Kerr, W. R., \& Dalton, M. (2019). Risk attitudes and personality traits of entrepreneurs and venture team members. Proceedings of the National Academy of Sciences, 201908375. https://doi.org/10.1073/pnas.1908375116 
Lauriola, M., \& Levin, I. P. (2001). Personality traits and risky decision-making in a controlled experimental task: An exploratory study. Personality and Individual Differences, 31(2), 215-226. https://doi.org/10.1016/S0191-8869(00)00130-6

Lauriola, M., \& Weller, J. A. (2018). Personality and Risk: Beyond Daredevils- Risk Taking from a a Temperament Perspective. In Psychological Perspectives on Risk and Risk Analysis: Theory, Models, and Applications (pp. 3-36).

Lee, K., Ogunfowora, B., \& Ashton, M. C. (2005). Personality traits beyond the Big Five: Are they within the HEXACO space? Journal of Personality, 73(5), 1437-1463.

Lejuez, C. W., Aklin, W. M., Zvolensky, M. J., \& Pedulla, C. M. (2003). Evaluation of the Balloon Analogue Risk Task (BART) as a predictor of adolescent real-world risk-taking behaviours. Journal of Adolescence, 26(4), 475-479.

Lerner, J. S., \& Keltner, D. (2001). Fear, anger, and risk. Journal of Personality and Social Psychology, 81(1), 146.

Maples-Keller, J. L., Williamson, R. L., Sleep, C. E., Carter, N. T., Campbell, W. K., \& Miller, J. D. (2019). Using Item Response Theory to Develop a 60-Item Representation of the NEO PI-R Using the International Personality Item Pool: Development of the IPIP-NEO-60. Journal of Personality Assessment, 101(1), 4-15. https://doi.org/10.1080/00223891.2017.1381968

Markon, K. E., Krueger, R. F., \& Watson, D. (2005). Delineating the Structure of Normal and Abnormal Personality: An Integrative Hierarchical Approach. Journal of Personality and Social Psychology, 88(1), 139-157. https://doi.org/10.1037/0022-3514.88.1.139 
Mata, R., Frey, R., Richter, D., Schupp, J., \& Hertwig, R. (2018). Risk Preference: A View from Psychology. Journal of Economic Perspectives, 32(2), 155-172. https://doi.org/10.1257/jep.32.2.155

McCrae, R. R., \& Costa Jr, P. T. (1999). A five-factor theory of personality. Handbook of Personality: Theory and Research, 2, 139-153.

Millroth, P., Juslin, P., Winman, A., Nilsson, H., \& Lindskog, M. (2020). Preference or ability: Exploring the relations between risk preference, personality, and cognitive abilities. Journal of Behavioral Decision Making, n/a(n/a). https://doi.org/10.1002/bdm.2171

Mishra, S., Lalumière, M. L., \& Williams, R. J. (2010). Gambling as a form of risk-taking: Individual differences in personality, risk-accepting attitudes, and behavioral preferences for risk. Personality and Individual Differences. https://doi.org/10.1016/j.paid.2010.05.032

Nicholson, N., Soane, E., Fenton-O’Creevy, M., \& Willman, P. (2005). Personality and domainspecific risk taking. Journal of Risk Research, 8(2), 157-176. https://doi.org/10.1080/1366987032000123856

O’Boyle, E. H., Forsyth, D. R., Banks, G. C., Story, P. A., \& White, C. D. (2015). A MetaAnalytic Test of Redundancy and Relative Importance of the Dark Triad and Five-Factor Model of Personality: Dark Triad and the Five-Factor Model. Journal of Personality, 83(6), 644-664. https://doi.org/10.1111/jopy.12126

Paunonen, S. V., \& Jackson, D. N. (2000). What is beyond the big five? Plenty! Journal of Personality, 68(5), 821-835. 
Pedroni, A., Frey, R., Bruhin, A., Dutilh, G., Hertwig, R., \& Rieskamp, J. (2017). The risk elicitation puzzle. Nature Human Behaviour, 1(11), 803-809. https://doi.org/10.1038/s41562-017-0219-x

Soto, C. J., \& John, O. P. (2017). The next Big Five Inventory (BFI-2): Developing and assessing a hierarchical model with 15 facets to enhance bandwidth, fidelity, and predictive power. Journal of Personality and Social Psychology, 113(1), 117.

Spector, P. E. (2006). Method variance in organizational research: Truth or urban legend? Organizational Research Methods, 9(2), 221-232.

Szrek, H., Chao, L.-W., Ramlagan, S., \& Peltzer, K. (2012). Predicting (un)healthy behavior: A comparison of risk-taking propensity measures. Judgment and Decision Making, 7(6), $716-727$.

Tonidandel, S., \& LeBreton, J. M. (2011). Relative Importance Analysis: A Useful Supplement to Regression Analysis. Journal of Business and Psychology, 26(1), 1-9. https://doi.org/10.1007/s10869-010-9204-3

Weber, E. U., Blais, A.-R., \& Betz, N. E. (2002). A domain-specific risk-attitude scale: Measuring risk perceptions and risk behaviors. Journal of Behavioral Decision Making, $15(4), 263-290$.

Weller, J. A., \& Tikir, A. (2011). Predicting domain-specific risk taking with the HEXACO personality structure. Journal of Behavioral Decision Making, 24(2), 180-201. https://doi.org/10.1002/bdm.677

Zhang, D. C., Highhouse, S., \& Nye, C. D. (2019). Development and validation of the general risk propensity scale (GRiPS). Journal of Behavioral Decision Making, 32(2), 152-167. 
Zuckerman, M., Kuhlman, D. M., Joireman, J., Teta, P., \& Kraft, M. (1993). A comparison of three structural models for personality: The big three, the big five, and the alternative five. Journal of Personality and Social Psychology, 65(4), 757. 
Table 1.

Means, standard deviations, and correlations, and scale reliabilities for Sample 1

\begin{tabular}{|c|c|c|c|c|c|c|c|c|c|c|c|c|c|c|c|}
\hline Variable & $M$ & $S D$ & 1 & 2 & 3 & 4 & 5 & 6 & 7 & 8 & 9 & 10 & 11 & 12 & 13 \\
\hline 1. Agreeable & 3.80 & 0.55 & $(.78)$ & & & & & & & & & & & & \\
\hline 2. Extraversion & 3.48 & 0.67 & .02 & $(.83)$ & & & & & & & & & & & \\
\hline 3. Conscientious & 3.50 & 0.67 & $.29 * *$ & $.30 * *$ & $(.86)$ & & & & & & & & & & \\
\hline 4. Neg. Emotion & 2.92 & 0.79 & $-.22 * *$ & $-.23 * *$ & $-.30 * *$ & $(.88)$ & & & & & & & & & \\
\hline 5. Openness & 3.63 & 0.61 & $.17^{*}$ & $.24 * *$ & .06 & .11 & $(.81)$ & & & & & & & & \\
\hline 6. DSP-Social & 4.69 & 1.04 & $-.16^{*}$ & $.26^{* *}$ & $-.23 * *$ & -.01 & $.37 * *$ & $(.70)$ & & & & & & & \\
\hline 7. DSP-Finance & 2.58 & 1.13 & $-.18^{* *}$ & .09 & $-.14^{*}$ & -.13 & .06 & $.21 * *$ & $(.80)$ & & & & & & \\
\hline 8. DSP-Recreation & 3.90 & 1.55 & .00 & $.34 * *$ & -.11 & $-.16^{*}$ & $.16^{*}$ & $.40 * *$ & $.37 * *$ & $(.82)$ & & & & & \\
\hline 9. DSP-Health & 3.36 & 1.28 & $-.24 * *$ & $.19 * *$ & $-.25 * *$ & .05 & .01 & $.40 * *$ & $.36^{* *}$ & $.56^{* *}$ & $(.70)$ & & & & \\
\hline 10. DSP-Ethics & 2.32 & 0.92 & $-.38 * *$ & -.03 & $-.35 * *$ & .11 & -.06 & $.30 * *$ & $.41 * *$ & $.28 * *$ & $.54 * *$ & $(.65)$ & & & \\
\hline 11. DSP-Total & 3.38 & 0.86 & $-.24 * *$ & $.27 * *$ & $-.29 * *$ & -.07 & $.15^{*}$ & $.64 * *$ & $.66^{* *}$ & $.79 * *$ & $.82 * *$ & $.66^{* *}$ & $(.88)$ & & \\
\hline 12. GRiPS & 2.91 & 0.94 & $-.22 * *$ & $.39 * *$ & -.12 & $-.16^{*}$ & .09 & $.30 * *$ & $.43^{* *}$ & $.54 * *$ & $.52 * *$ & $.36^{* *}$ & $.63^{* *}$ & $(.91)$ & \\
\hline 13. Age & 19.26 & 1.38 & -.09 & .04 & $.16^{*}$ & -.09 & -.00 & .06 & .03 & -.05 & .01 & .01 & .01 & -.02 & \\
\hline 14. Gender & 1.70 & 0.49 & $.22 * *$ & $.14^{*}$ & $.17^{*}$ & $.24 * *$ & $.13^{*}$ & .01 & $-.32 * *$ & -.12 & $-.17 * *$ & $-.23 * *$ & $-.22 * *$ & $-.14^{*}$ & .08 \\
\hline
\end{tabular}

Note. $M$ and $S D$ are used to represent mean and standard deviation, respectively. * indicates $p<.05$. ** indicates $p<$

.01. DSP = DOSPERT. GRiPS = General Risk Propensity Scale. Diagonals contain Cronbach’s alpha. 
Table 2.

Means, standard deviations, and correlations, and scale reliabilities for Sample 2

\begin{tabular}{|c|c|c|c|c|c|c|c|c|c|c|c|c|c|c|c|}
\hline Variable & $M$ & $S D$ & 1 & 2 & 3 & 4 & 5 & 6 & 7 & 8 & 9 & 10 & 11 & 12 & 13 \\
\hline 1. Neuroticism & 3.00 & 0.74 & $(.85)$ & & & & & & & & & & & & \\
\hline 2. Extraversion & 3.10 & 0.72 & $-.47 * *$ & $(.85)$ & & & & & & & & & & & \\
\hline 3. Openness & 3.53 & 0.59 & 0.02 & $.19 * *$ & $(.74)$ & & & & & & & & & & \\
\hline 4. Agreeableness & 3.86 & 0.54 & $-.11 *$ & 0.00 & $.22 * *$ & $(.79)$ & & & & & & & & & \\
\hline 5. Conscientiousness & 3.73 & 0.60 & $-.48 * *$ & $.38 * *$ & 0.04 & $.31 * *$ & $(.84)$ & & & & & & & & \\
\hline 6. DOSP-Social & 4.98 & 1.05 & $-.10 *$ & $.26 * *$ & $.50 * *$ & 0.01 & $0.09 *$ & $(.68)$ & & & & & & & \\
\hline 7. DOSP-Recreation & 2.78 & 1.43 & $-.13 * *$ & $.39 * *$ & $.20 * *$ & $-.15 * *$ & 0.01 & $.36 * *$ & $(.85)$ & & & & & & \\
\hline 8. DOSP-Finance & 2.46 & 1.22 & $-.12 * *$ & $.22 * *$ & $.19 * *$ & $-.25 * *$ & -0.04 & $.27 * *$ & $.41 * *$ & $(.82)$ & & & & & \\
\hline 9. DOSP-Heath & 2.97 & 1.14 & $.10^{*}$ & $.17 * *$ & $.11 *$ & $-.27 * *$ & $-.23 * *$ & $.30 * *$ & $.45^{* *}$ & $.32 * *$ & $(.67)$ & & & & \\
\hline 10. DOSP-Ethics & 2.33 & 1.00 & $.22 * *$ & -0.01 & 0.01 & $-.44 * *$ & $-.38 * *$ & $.16^{* *}$ & $.24 * *$ & $.34 * *$ & $.52 * *$ & $(.69)$ & & & \\
\hline 11. DOSP-Total & 3.22 & 0.78 & -0.02 & $.32 * *$ & $.29 * *$ & $-.31 * *$ & $-.15 * *$ & $.59 * *$ & $.76^{* *}$ & $.69 * *$ & $.75^{* *}$ & $.63 * *$ & $(.88)$ & & \\
\hline 12. GRiPS & 2.53 & 0.94 & $-.16 * *$ & $.44 * *$ & $.25 * *$ & $-.24 * *$ & -0.08 & $.36 * *$ & $.57 * *$ & $.47 * *$ & $.44 * *$ & $.31 * *$ & $.63 * *$ & $(.93)$ & \\
\hline 13. Age & 36.19 & 12.91 & $-.17 * *$ & -0.06 & $-.09 *$ & $.18 * *$ & $.17 * *$ & -0.03 & $-.27 * *$ & $-.14 * *$ & $-.19 * *$ & $-.15 * *$ & $-.23 * *$ & $-.23 * *$ & \\
\hline 14. Sex & 0.50 & 0.50 & $-.15 * *$ & 0.01 & -0.02 & $-.29 * *$ & $-.13 * *$ & 0.02 & $.18 * *$ & $.26 * *$ & $.27 * *$ & $.17 * *$ & $.26 * *$ & $.23 * *$ & $-.09 *$ \\
\hline
\end{tabular}

Note. $M$ and $S D$ are used to represent mean and standard deviation, respectively. $*$ indicates $p<.05 . * *$ indicates $p<.01$. DSP $=$ DOSPERT.

GRiPS $=$ General Risk Propensity Scale. Diagonals contain Cronbach’s alpha. 
Table 3.

BFI-2 facets and domain-general risk-taking propensity from Sample 1

\begin{tabular}{|c|c|c|c|c|c|c|c|}
\hline \multirow[t]{2}{*}{ BFI Facet } & \multirow[b]{2}{*}{ Reliability } & \multicolumn{3}{|l|}{ GRiPS } & \multicolumn{3}{|c|}{ DOSPERT-Total } \\
\hline & & $\beta$ & $r$ & R.I. & $\beta$ & $r$ & R.I. \\
\hline C: Responsibility & .65 & $-.71 * *$ & $-.45 * *$ & $37.0 \%$ & $-.50 * *$ & $-.42 * *$ & $36.0 \%$ \\
\hline E: Sociability & .84 & $.22 * *$ & $.35^{* *}$ & $14.8 \%$ & .16 & $.26^{* *}$ & $9.5 \%$ \\
\hline E: Assertiveness & .72 & .12 & $.35^{* *}$ & $9.4 \%$ & .01 & $.25 * *$ & $6.5 \%$ \\
\hline E: Energy Level & .65 & .02 & $.26^{* *}$ & $8.7 \%$ & .02 & $.14^{*}$ & $3.6 \%$ \\
\hline $\mathrm{N}$ : Anxiety & .72 & $-.28 *$ & $-.20 * *$ & $6.9 \%$ & -.14 & -.10 & $3.8 \%$ \\
\hline A: Respectfulness & .64 & -.15 & $-.28 * *$ & $6.7 \%$ & -.15 & $-.28 * *$ & $8.9 \%$ \\
\hline O: Intellectual Curiosity & .67 & $.24^{*}$ & $.17^{*}$ & $3.2 \%$ & $.19^{*}$ & $.22 * *$ & $8.9 \%$ \\
\hline C: Productiveness & .73 & -.11 & -.08 & $2.9 \%$ & -.03 & $-.17 *$ & $4.3 \%$ \\
\hline N: Depression & .81 & -.00 & $-.15^{*}$ & $2.2 \%$ & -.03 & -.03 & $0.8 \%$ \\
\hline C: Organization & .82 & $.17 *$ & -.01 & $1.9 \%$ & -.06 & $-.20 * *$ & $5.4 \%$ \\
\hline A: Compassion & .50 & .06 & $-.16^{*}$ & $1.6 \%$ & -.10 & $-.20 * *$ & $5.5 \%$ \\
\hline A: Trust & .61 & -.11 & -.10 & $1.6 \%$ & -.01 & -.10 & $1.1 \%$ \\
\hline O: Creative Imagination & .68 & .00 & .12 & $1.1 \%$ & .10 & $.15^{*}$ & $3.8 \%$ \\
\hline N: Emotional Volatility & .80 & .00 & -.06 & $1.0 \%$ & .04 & .05 & $0.9 \%$ \\
\hline O: Aesthetic Sensitivity & .73 & -.05 & -.05 & $0.8 \%$ & -.00 & .07 & $0.9 \%$ \\
\hline Multiple $R^{2}$ & & .42 & & & .33 & & \\
\hline
\end{tabular}

Notes. $\mathrm{E}=$ extraversion; $\mathrm{A}=$ agreeableness; $\mathrm{C}=$ conscientiousness; $\mathrm{N}=$ negative emotionality; $\mathrm{O}=$ openmindedness. Facets sorted by the magnitude of relative importance for predicting GRiPS. R.I. = relative importance. * indicates $p<.05 . * *$ indicates $p<.01$. 
Table 4.

NEO-PI-60 facets and domain-general risk-taking propensity from Sample 2

\begin{tabular}{|c|c|c|c|c|c|c|c|}
\hline \multirow[t]{2}{*}{ NEO Facet } & \multirow[b]{2}{*}{ Reliability } & \multicolumn{3}{|l|}{ GRiPS } & \multicolumn{3}{|c|}{ DOSPERT-Total } \\
\hline & & $\beta$ & $r$ & R.I. & $\beta$ & $r$ & R.I. \\
\hline C: Cautious & .87 & $-.36 * *$ & $-.35 * *$ & $30.1 \%$ & $-.12 * *$ & $-.16 * *$ & $16.5 \%$ \\
\hline E: Gregarious & .77 & $.21 * *$ & $.35 * *$ & $17.5 \%$ & $.16^{* *}$ & $.25 * *$ & $9.9 \%$ \\
\hline $\mathrm{N}$ : Anxiety & .79 & $-.25 * *$ & $-.25 * *$ & $12.2 \%$ & $-.19 * *$ & $-.15 * *$ & $7.0 \%$ \\
\hline E: Assertive & .89 & $.13^{* *}$ & $.30 * *$ & $11.1 \%$ & $.22 * *$ & $.33 * *$ & $19.2 \%$ \\
\hline A: Cooperation & .74 & $-.12 * *$ & $-.26 * *$ & $9.3 \%$ & $-.25 * *$ & $-.35 * *$ & $21.0 \%$ \\
\hline O: Imagination & .77 & $.14 * *$ & $.21^{* *}$ & $7.3 \%$ & $.12 * *$ & $.20 * *$ & $5.4 \%$ \\
\hline O: Intellect & .82 & $.11^{*}$ & $.14^{* *}$ & $3.8 \%$ & $.12 * *$ & $.20 * *$ & $7.4 \%$ \\
\hline E: Activity & .88 & .04 & $.14 * *$ & $2.1 \%$ & -.03 & .00 & $0.5 \%$ \\
\hline C: Orderliness & .81 & -.02 & $-.10 *$ & $1.6 \%$ & $-.08^{*}$ & $-.17 *$ & $3.5 \%$ \\
\hline N: Depression & .77 & $.10^{*}$ & -.08 & $1.4 \%$ & $.17 * *$ & .06 & $3.0 \%$ \\
\hline O: Artistic & .91 & .01 & $.10^{*}$ & $1.2 \%$ & .08 & $.16^{* *}$ & $4.2 \%$ \\
\hline $\mathrm{N}$ : Anger & .89 & -.02 & -.01 & $0.9 \%$ & .01 & .06 & $0.8 \%$ \\
\hline C: Discipline & .50 & .06 & .06 & $0.6 \%$ & -.02 & -.04 & $0.7 \%$ \\
\hline A: Sympathy & .86 & -.01 & -.04 & $0.4 \%$ & .04 & .01 & $0.5 \%$ \\
\hline A: Trust & .86 & -.02 & .02 & $0.3 \%$ & -.02 & -.02 & $0.3 \%$ \\
\hline Multiple $R^{2}$ & & .38 & & & .37 & & \\
\hline
\end{tabular}

Notes. $\mathrm{E}=$ extraversion; $\mathrm{A}=$ agreeableness; $\mathrm{C}=$ conscientiousness; $\mathrm{N}=$ negative emotionality; $\mathrm{O}=$ openmindedness. Facets sorted by the magnitude of relative importance for predicting GRiPS. R.I. = relative importance. ${ }^{*}$ indicates $p<.05 .{ }^{* *}$ indicates $p<.01$. 
Table 5.

BFI-2 facets and domain-specific risk-taking propensity

\begin{tabular}{|c|c|c|c|c|c|c|c|c|c|c|c|c|c|c|c|}
\hline \multirow{2}{*}{ Big Five Facet } & \multicolumn{3}{|c|}{ DOSPERT-Social } & \multicolumn{3}{|c|}{ DOSPERT-Ethics } & \multicolumn{3}{|c|}{ DOSPERT-Finance } & \multicolumn{3}{|c|}{ DOSPERT-Recreational } & \multicolumn{3}{|c|}{ DOSPERT-Health } \\
\hline & $\beta$ & $r$ & R.I & $\bar{\beta}$ & $r$ & R.I & $\beta$ & $r$ & R.I & $\bar{\beta}$ & $r$ & R.I & $\beta$ & $r$ & R.I \\
\hline $\mathrm{N}$ : Anxiety & -.08 & -.03 & $1.3 \%$ & -.14 & -.02 & $3.4 \%$ & -.07 & $-.16^{*}$ & $6.7 \%$ & -.07 & $-.16^{*}$ & $3.9 \%$ & $-.22 *$ & -.07 & $6.3 \%$ \\
\hline N: Depression & -.08 & -.03 & $1.3 \%$ & .03 & $.15^{*}$ & $2.1 \%$ & -.08 & -.10 & $3.7 \%$ & -.07 & $-.19 * *$ & $4.5 \%$ & $.19^{*}$ & .10 & $4.7 \%$ \\
\hline $\begin{array}{l}\text { N: Emotional } \\
\text { Volatility }\end{array}$ & .06 & .08 & $1.1 \%$ & .08 & $.14 *$ & $2.5 \%$ & -.09 & -.11 & $4.8 \%$ & -.04 & -.08 & $1.3 \%$ & .03 & .10 & $1.8 \%$ \\
\hline E: Sociability & -.04 & $.16^{*}$ & $2.8 \%$ & .07 & .01 & $1.3 \%$ & .08 & .06 & $1.0 \%$ & .13 & $.33 * *$ & $13.9 \%$ & $.26^{* *}$ & $.22 * *$ & $14.7 \%$ \\
\hline E: Energy Level & .09 & $.15^{*}$ & $3.5 \%$ & -.12 & $-.16^{*}$ & $4.2 \%$ & -.10 & .04 & $1.1 \%$ & .05 & $.30 * *$ & $10.1 \%$ & .04 & .09 & $3.0 \%$ \\
\hline E: Assertiveness & $-20 * *$ & $.30 * *$ & $12.7 \%$ & .07 & .02 & $1.4 \%$ & -.15 & .08 & $2.2 \%$ & .11 & $.31 * *$ & $11.8 \%$ & -.08 & .12 & $2.7 \%$ \\
\hline O: Creativity & .11 & $.29 * *$ & $11.1 \%$ & -.02 & -.10 & $1.0 \%$ & $.18^{*}$ & .11 & $9.7 \%$ & .09 & $.21 * *$ & $6.2 \%$ & -.00 & -.00 & $0.2 \%$ \\
\hline O: Intellect & .12 & $.24 * *$ & $9.1 \%$ & .10 & .01 & $1.4 \%$ & -.12 & -.06 & $3.2 \%$ & -.05 & -.01 & $0.6 \%$ & .01 & -.01 & $0.2 \%$ \\
\hline $\begin{array}{l}\text { O: Aesthetic } \\
\text { Sensitivity }\end{array}$ & $.17 *$ & $.36 * *$ & $18.3 \%$ & -.07 & -.06 & $0.9 \%$ & $.19^{*}$ & .12 & $10.2 \%$ & .12 & $.20 * *$ & $6.4 \%$ & .07 & .05 & $0.9 \%$ \\
\hline A: Trust & -.12 & $-.14 *$ & $3.6 \%$ & -.05 & $-.24 * *$ & $6.4 \%$ & .12 & -.04 & $2.5 \%$ & .02 & .07 & $0.9 \%$ & -.03 & -.11 & $1.6 \%$ \\
\hline A: Compassion & .00 & -.07 & $0.8 \%$ & $-.16^{*}$ & $-.34 * *$ & $19.0 \%$ & -.15 & $-.22 * *$ & $15.3 \%$ & .08 & .00 & $0.9 \%$ & -.07 & $-.22 * *$ & $7.4 \%$ \\
\hline A: Respect & -.04 & $-.21 * *$ & $4.6 \%$ & -.12 & $-.36 * *$ & $16.7 \%$ & $-.22 *$ & $-.21 * *$ & $16.6 \%$ & -.02 & -.08 & $1.7 \%$ & -.12 & $-.27 * *$ & $10.1 \%$ \\
\hline C: Organization & $-.22 * *$ & $-.28 * *$ & $15.9 \%$ & -.08 & $-.24 * *$ & $7.9 \%$ & .01 & -.07 & $1.0 \%$ & -.05 & -.09 & $2.5 \%$ & .00 & $-.15^{*}$ & $2.4 \%$ \\
\hline C: Responsibility & -.11 & $-.22 * *$ & $6.8 \%$ & $-.18 *$ & $-.35 * *$ & $20.6 \%$ & $-.17 *$ & $-.23 * *$ & $19.4 \%$ & $-.35 * *$ & $-.31 * *$ & $33.7 \%$ & $-.30 * *$ & $-.42 * *$ & $39.8 \%$ \\
\hline C: Productive & -.11 & $-.18 * *$ & $6.5 \%$ & -.04 & $-.32 * *$ & $11.1 \%$ & .02 & -.08 & $2.2 \%$ & -.00 & .00 & $1.3 \%$ & .02 & $-.18 * *$ & $3.8 \%$ \\
\hline Multiple $R^{2}$ & 0.33 & & & 0.25 & & & 0.18 & & & 0.28 & & & 0.26 & & \\
\hline
\end{tabular}

Notes. $\mathrm{E}=$ Extraversion; $\mathrm{A}=$ Agreeableness; $\mathrm{C}=$ Conscientiousness; $\mathrm{N}=$ Negative Emotionality; $\mathrm{O}=\mathrm{Open}$

mindedness. $*$ indicates $p<.05 ; * *$ indicates $p<.01 ;$ R.I. $=$ relative importance 
Table 6.

NEO-PI-60 facets and domain-specific risk-taking propensity

\begin{tabular}{|c|c|c|c|c|c|c|c|c|c|c|c|c|c|c|c|}
\hline \multirow{2}{*}{ NEO Facet } & \multicolumn{3}{|c|}{ DOSPERT-Social } & \multicolumn{3}{|c|}{ DOSPERT-Ethics } & \multicolumn{3}{|c|}{ DOSPERT-Finance } & \multicolumn{3}{|c|}{ DOSPERT-Recreational } & \multicolumn{3}{|c|}{ DOSPERT-Health } \\
\hline & $\beta$ & $r$ & R.I & $\beta$ & $r$ & R.I & $\bar{\beta}$ & $r$ & R.I & $\beta$ & $r$ & R.I & $\bar{\beta}$ & $r$ & R.I \\
\hline $\mathrm{N}$ : Anxiety & -.10 & $-.10^{*}$ & $2.4 \%$ & -.04 & .06 & $0.6 \%$ & $-.12 *$ & $-.18 * *$ & $9.9 \%$ & $-.23 * *$ & $-.22 * *$ & $16.4 \%$ & $-.15^{* *}$ & -.04 & $4.3 \%$ \\
\hline $\mathrm{N}$ : Anger & .01 & -.04 & $0.3 \%$ & .00 & $.20 * *$ & $3.9 \%$ & -.07 & -.05 & $2.1 \%$ & -.01 & -.02 & $0.7 \%$ & .05 & $.16^{* *}$ & $3.7 \%$ \\
\hline N: Depress & .08 & .03 & $1.3 \%$ & .06 & $.16^{* *}$ & $2.9 \%$ & .00 & -.07 & $1.2 \%$ & $.18^{* *}$ & -.02 & $4.4 \%$ & $.20 * *$ & $.14 * *$ & $7.5 \%$ \\
\hline E: Gregarious & -.01 & .09 & $0.7 \%$ & .07 & .07 & $2.6 \%$ & .06 & $.17^{* *}$ & $6.6 \%$ & $.18^{* *}$ & $.28^{* *}$ & $20.2 \%$ & $.19^{* *}$ & $.20^{* *}$ & $14.4 \%$ \\
\hline E: Assertiveness & $.26^{* *}$ & $.33^{* *}$ & $22.5 \%$ & .03 & .06 & $1.4 \%$ & $.13^{* *}$ & $.23^{* *}$ & $15.2 \%$ & $.17 * *$ & $.30^{* *}$ & $23.4 \%$ & $.13^{* *}$ & $.19^{* *}$ & $10.4 \%$ \\
\hline E: Activity & -.03 & .04 & $0.3 \%$ & -.07 & $-.12 * *$ & $2.8 \%$ & -.06 & .01 & $0.9 \%$ & .03 & $.10^{*}$ & $1.5 \%$ & -.06 & -.04 & $1.0 \%$ \\
\hline O: Imagination & $.09^{*}$ & $.30^{* *}$ & $11.1 \%$ & .04 & .04 & $0.7 \%$ & .05 & $.15^{* *}$ & $5.3 \%$ & .03 & $.11^{*}$ & $2.1 \%$ & .09 & $.11^{*}$ & $3.3 \%$ \\
\hline O: Artistic & $.23 * *$ & $.39^{* *}$ & $24.2 \%$ & -.04 & $-.09 *$ & $1.1 \%$ & $.14 * *$ & $.17 * *$ & $10.2 \%$ & .05 & $.11^{*}$ & $2.9 \%$ & -.07 & -.02 & $0.7 \%$ \\
\hline O: Intellect & $.21 * *$ & $.37 * *$ & $21.8 \%$ & .03 & -.02 & $0.2 \%$ & $.10^{*}$ & $.16^{* *}$ & $7.9 \%$ & $.09^{*}$ & $.14^{* *}$ & $5.7 \%$ & .06 & .06 & $1.4 \%$ \\
\hline A: Trust & $-.09 *$ & -.01 & $1.3 \%$ & .02 & $-.10^{*}$ & $0.8 \%$ & -.02 & .00 & $0.4 \%$ & .05 & .08 & $1.6 \%$ & -.02 & -.08 & $0.9 \%$ \\
\hline A: Cooperation & -.03 & -.04 & $0.8 \%$ & $-.32 * *$ & $-.42 * *$ & $43.5 \%$ & $-.21 * *$ & $-.24 * *$ & $24.9 \%$ & $-.13 * *$ & $-.20 * *$ & $11.7 \%$ & $-.14 * *$ & $-.31 * *$ & $17.5 \%$ \\
\hline A: Sympathy & $.12^{* *}$ & $.22 * *$ & $7.4 \%$ & -.03 & $-.12 * *$ & $2.2 \%$ & -.02 & -.02 & $0.6 \%$ & -.01 & .00 & $0.2 \%$ & .02 & -.04 & $0.3 \%$ \\
\hline C: Orderliness & -.08 & $-.09 *$ & $2.2 \%$ & -.04 & $-.22 * *$ & $6.1 \%$ & .01 & -.06 & $0.9 \%$ & .01 & -.04 & $0.4 \%$ & $-.09 *$ & $-.21 * *$ & $7.9 \%$ \\
\hline C: Cautious & $-.10^{*}$ & -.05 & $1.7 \%$ & $-.20 * *$ & $-.23 * *$ & $23.1 \%$ & $-.17 * *$ & $-.16^{* *}$ & $13.4 \%$ & $-.13^{* *}$ & $-.14^{* *}$ & $8.3 \%$ & $-.23 * *$ & $-.33 * *$ & $24.7 \%$ \\
\hline C: Discipline & $.11^{*}$ & $.09^{*}$ & $1.8 \%$ & $-.10^{* *}$ & $-.24 * *$ & $8.1 \%$ & .02 & .03 & $0.5 \%$ & -.01 & .03 & $0.5 \%$ & .01 & $-.11 * *$ & $1.7 \%$ \\
\hline Multiple $R^{2}$ & 0.34 & & & 0.27 & & & 0.19 & & & 0.22 & & & 0.26 & & \\
\hline
\end{tabular}

Notes. $\mathrm{E}=$ Extraversion; $\mathrm{A}=$ Agreeableness; $\mathrm{C}$ = Conscientiousness; $\mathrm{N}=$ Negative Emotionality; $\mathrm{O}=$ Open

mindedness. $*$ indicates $p<.05 ; * *$ indicates $p<.01 ;$ R.I. $=$ relative importance 


\section{Appendix A}

Facet Correspondence between BFI and NEO-PI-R

\begin{tabular}{lll}
\hline Big Five Dimension & BFI-2 Facet & IPIP-NEO-60 Facets \\
\hline Extraversion & Sociability & Gregariousness \\
& Assertiveness & Assertiveness \\
& Energy Level & Activity Level \\
Agreeableness & Compassion & Sympathy \\
& Respectfulness & Cooperation \\
Conscientiousness & Trust & Trust \\
& Organization & Orderliness \\
Neuroticism & Productiveness & Discipline \\
& Responsibility & Cautious \\
& Anxiety & Anxiety \\
Openness & Depression & Depression \\
& Emotional Volatility & Anger \\
& Intellect & Intellect \\
& Aesthetic Sensitivity & Artistic Interests \\
\hline
\end{tabular}

